\title{
ERRATUM
}

\section{Ophthalmological outcomes of patients treated for pineal region tumors}

TO THE EDITOR: An error occurred during preparation of our article, "Ophthalmological outcomes of patients treated for pineal region tumors" ( $J$ Neurosurg Pediatr [epub ahead of print January 22, 2016; DOI: 10.3171/2015.10.PEDS15415]). The figure legends for Figs. 1 and 2 were mistakenly switched.

We regret this error, and we appreciate the opportunity to correct it. The article has been corrected online as of March 25, 2016, to show the appropriate legends below Figs. 1 and 2; and the corrected figure and legend placements are displayed here.

David D. Cochrane, MD, FRCSC University of British Columbia and British Columbia's Children's Hospital, Vancouver, BC, Canada

CORRESPONDING ARTICLE See pp 558-563.

INCLUDE WHEN CITING

Published online March 25, 2016; DOI: 10.3171/2016.3.PEDS15415a.

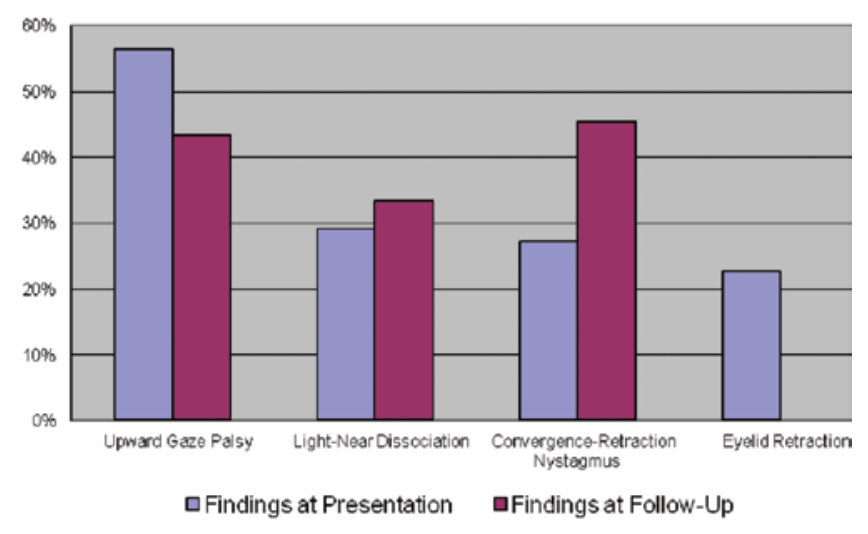

FIG. 1. Comparison of the frequencies of the components of Parinaud's syndrome in patients whose definitive treatment included surgical resection (20 patients with NGGCT, teratoma, or pineal parenchymal tumor). Figure is available in color online only.

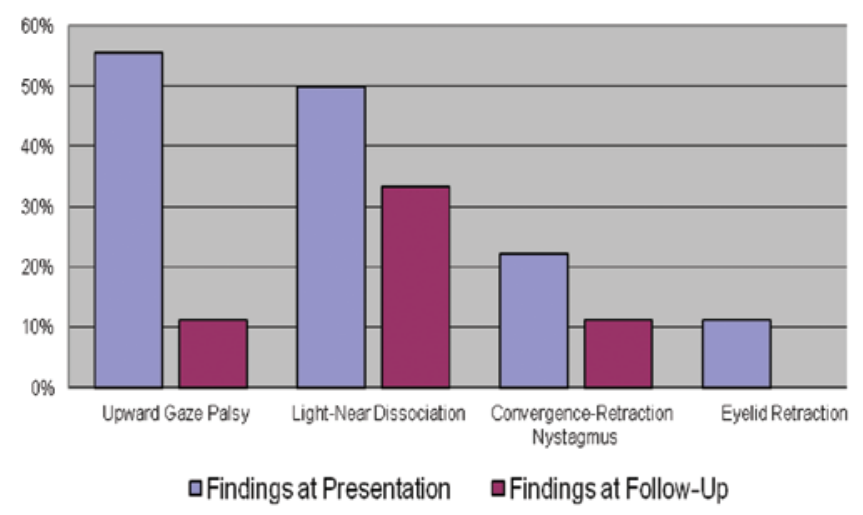

FIG. 2. Comparison of the frequencies of the components of Parinaud's syndrome in patients whose definitive treatment was chemotherapy and/ or radiotherapy ( 9 patients with germinomas). Figure is available in color online only. 